\title{
The use of reimbursement data for timely monitoring of vaccination coverage: the example of human papillomavirus vaccine following public concerns about vaccine safety
}

\author{
Laure Fonteneau $^{1,2}$, Marine Ragot ${ }^{1}$, Isabelle Parent du Châtelet ${ }^{1}$, Jean-Paul Guthmann ${ }^{1}$ and Daniel Lévy-Bruhl ${ }^{1 *}$
}

\begin{abstract}
Background: Since 2011 public concerns about Human Papillomavirus (HPV) vaccination safety and efficacy arose in France. We explored the relevance of using vaccines reimbursement data to assess the impact of those public concerns on vaccination coverage.

Methods: We used the Permanent Sample of Beneficiaries which was, at the time of the study, a representative sample of $1 / 97^{\text {th }}$ health insurance beneficiaries of the main Social Security scheme, the General Health Insurance Scheme, covering approximately $77 \%$ of the French resident population. We estimated HPV vaccination coverage among girls born between 1995 and 1999 at their $15^{\text {th }}, 16^{\text {th }}$ and $17^{\text {th }}$ birthday.

Results: The coverage for complete vaccination among 16 years old girls decreased from $26.5 \%$ in the first semester of 2011 to $18.6 \%$ in the first semester of 2014.

Conclusions: HPV vaccination coverage was already low in 2011 and continued to decrease thereafter. Vaccines reimbursement data allowed us to reactively monitor the impact of the controversy on vaccination coverage and design counteracting measures.
\end{abstract}

Keywords: Vaccination, Papillomavirus, France, Vaccine coverage, Rreimbursement data

\section{Background}

In 2012, cervical cancer was the 11th most common cancer in women in France with 3028 estimated new cases and the $12^{\text {th }}$ in terms of mortality with an estimated 1102 deaths [1]. The human papillomavirus (HPV) is a necessary cause of cervical cancer [2]. In addition to the opportunistic screening strategy based on Pap smears recommended every 3 years for women 25 to 65 years old, HPV vaccination was introduced in the immunisation schedule in 2007. Up to 2013, vaccination was recommended for girls aged 14 years old, with a catch-up offered for girls aged 15-23 years old who

* Correspondence: d.levybruhl@invs.sante.fr

${ }^{1}$ Institut de Veille Sanitaire (InVS), Saint-Maurice, France

Full list of author information is available at the end of the article had not started their sexual life or in the year following their sexual life debut [3]. Three doses were required for a complete vaccination course [4].

In summer 2011, articles questioning HPV vaccine safety were published in the lay media, telling the stories of teenagers having developed neurological manifestations after HPV vaccination. A group of physicians opposed to HPV vaccination organized several manifestations including a public meeting with members of parliament, questioning the relevance of vaccination in addition to pre-cancerous lesions screening. In October 2011, the High Council for Public Health issued a statement reaffirming the favorable risk/benefit balance of HPV vaccination [5]. In autumn 2013 the debate was reopened with the decision of a Regional commission 
for compensation for medical accidents which concluded to the partial responsibility of the HPV vaccine in the development of multiple sclerosis in a vaccinated adolescent girl. This event was reported by the media.

Up to recently, the only routine source of vaccination coverage among teenagers were the national school surveys performed every six years at 15 years of age $[6,7]$. Although providing reliable results, they were limited by their poor timeliness. We therefore explored the relevance of using vaccine reimbursement data to closely monitor the impact of public concerns on HPV vaccination coverage.

\section{Methods}

HPV vaccination is almost exclusively administered in France through the private sector. Patients purchase the vaccine at pharmacies on a medical prescription. Virtually the whole French population is covered by the National Health Insurance Scheme (NHIS) which covers $65 \%$ of the price of the vaccine. A complementary insurance covers the remaining $35 \%$ of the vaccine cost for over $90 \%$ of the population. This reimbursement data are entered into a single database, the National Health Insurance Information System, which contains anonymous and comprehensive data on the health care consumption of the entire French population.

In order to give access to a manageable database to Public Health institutions, a sample of this huge database, called the Permanent Sample of Beneficiaries (PSB), was established in 2005. Through a decree signed by the Minister of Health in 2005, the National Institute for Public Health Surveillance (InVS) was given access to the PSB, together with a restricted list of public institutions. At that time, the PSB was a representative sample of $1 / 97^{\text {th }}$ health insurance beneficiaries covered by the main scheme, the General Health Insurance Scheme, covering approximately $77 \%$ of the French resident population. It included about 500,000 persons, followed for all their health care consumptions for a period of at least 20 years $[8,9]$.

We use the PSB to bi-annually monitor HPV vaccination coverage. The current analysis presents vaccination data for girls born between 1995 and 1999 and aged 15 years between January 2010 and June 2014. We estimated coverage at their $15^{\text {th }}, 16^{\text {th }}$ and $17^{\text {th }}$ birthday. We extracted data related to HPV vaccines purchased between July 2007 (date of first admission to reimbursement by the NHIS of a HPV vaccine) and June 2014. We extracted data from the date of the first admission to reimbursement as some girls may have been vaccinated before 14 years of age, the marketing authorization of both vaccines having been granted for girls from 9 years of age. To take into account a possible delay between vaccine purchase and availability of the information in the PSB, we extracted the data in October 2014. For each selected individual, we extracted his/her vaccine history (number of doses reimbursed and age at delivery). The age-specific vaccination coverage was calculated by dividing, for each dose of vaccine, the number of doses reimbursed by that age, by the number of eligible girls of that age in the PSB. In order to assess more precisely the potential impact of media on the HPV vaccination coverage we retrospectively estimate the vaccination coverage by quarter.

A decree dated 20th June 2005 gives to accredited InVS staff access to anonymized individual PSB data. This decree was issued after receiving a positive opinion from the French Data Protection Agency (CNIL). The author, who did the extraction and analysis, is accredited for PSB database access.

\section{Results}

The vaccine coverage for at least one dose at the $15^{\text {th }}$ birthday varied very little from $23.7 \%$ (95\% confidence interval, CI [20.9-26.5]) to $26.5 \%$ (95 \% CI [24.1-28.9]) between 2010 and 2011. It decreased from $25.6 \%$ (95\% CI [23.3-27.9]) in the second semester of 2011 to $16.3 \%$ (95 \% CI [14.3-18.3]) in the first semester of 2013 and has remained below $18 \%$ since (Table 1 and Fig. 1).

The vaccine coverage for the full series on the $16^{\text {th }}$ birthday varied very little from $26.5 \%$ (95 \% CI [23.629.4]) in the first half of 2011 to $28.2 \%$ (95 \% CI [25.8$30.6]$ ) in the first half of 2012. It decreased from $28.2 \%$ (95\% CI [25.8-30.6]) in the first semester of 2012 to $18.6 \%(95 \%$ CI [16.5-20.7]) in the first semester of 2014. Coverage slightly increased between the $16^{\text {th }}$ and $17^{\text {th }}$ birthday through a limited catch up. However the coverage among girls aged 17 years old decreased from 31.2 (95 \% CI [28.6-33.6]) to $26.3 \%$ (95 \% CI [24.328.6]) from the first semester of 2013 to the first semester of 2014 (Table 1). For girls born after 1996, the 3 doses vaccination coverage at any age decreased for successive birth cohorts (Fig. 2).

\section{Discussion}

Even for the 1995 birth cohort who reached 16 years of age at the time of the first publications in the lay media, the coverage at 16 years was below $30 \%$. The one dose $\mathrm{HPV}$ vaccine coverage dropped after the first publication from $25.6 \%$ at the end of 2011 to $19.8 \%$ at the beginning of 2012. We did not observe a second drop in vaccination coverage after the 2013 decision of a Regional commission for compensation for medical accidents in favor of the partial responsibility of the HPV vaccine in the development of multiple sclerosis in an adolescent girl. At this time the vaccination coverage was already very low (17.5\% for 1 dose) which could explain that it did not decreased further. Unfortunately, in 2011, the 
Table $1 \mathrm{HPV}$ vaccination coverage (\%) and its $95 \%$ confidence interval at $15^{\text {th }}, 16^{\text {th }}$ and $17^{\text {th }}$ birthday as of June 302014 , France

\begin{tabular}{|c|c|c|c|c|c|c|c|c|c|}
\hline \multirow{2}{*}{$\begin{array}{l}\text { Half year of } \\
\text { birthday }\end{array}$} & 2010 & 2010 & 2011 & 2011 & 2012 & 2012 & 2013 & 2013 & 2014 \\
\hline & s1 & $s 2$ & s1 & s2 & s1 & s2 & s1 & $s 2$ & s1 \\
\hline$n$ & 877 & 914 & 1316 & 1340 & 1431 & 1430 & 1323 & 1408 & 1404 \\
\hline 1 dose at 15 & 23.7 [20.9-26.5] & 24.7 [21.9-27.5] & 26.5 [24.1-28.9] & 25.6 [23.3-27.9] & 19.8 [17.1-21.9] & 17.5 [15.5-19.5] & 16.3 [14.3-18.3] & 17.5 [15.5-19.5] & 17.7 [15.7-19.7] \\
\hline 3 doses at 16 & - & - & $26.5[23.6-29.4]$ & 27.4 [24.5-30.3] & $28.2[25.8-30.6]$ & $24.2[21.9-26.5]$ & $22.0[19.9-24.1]$ & 20.1 [18.0-22.2] & 18.6 [16.5-20.7] \\
\hline 3 doses at 17 & - & - & - & - & $31.2[28.8-33.6]$ & $30.3[27.9-32.7]$ & $32.0[29.5-34.5]$ & $27.2[24.9-29.5]$ & 26.3 [24.0-28.6] \\
\hline
\end{tabular}




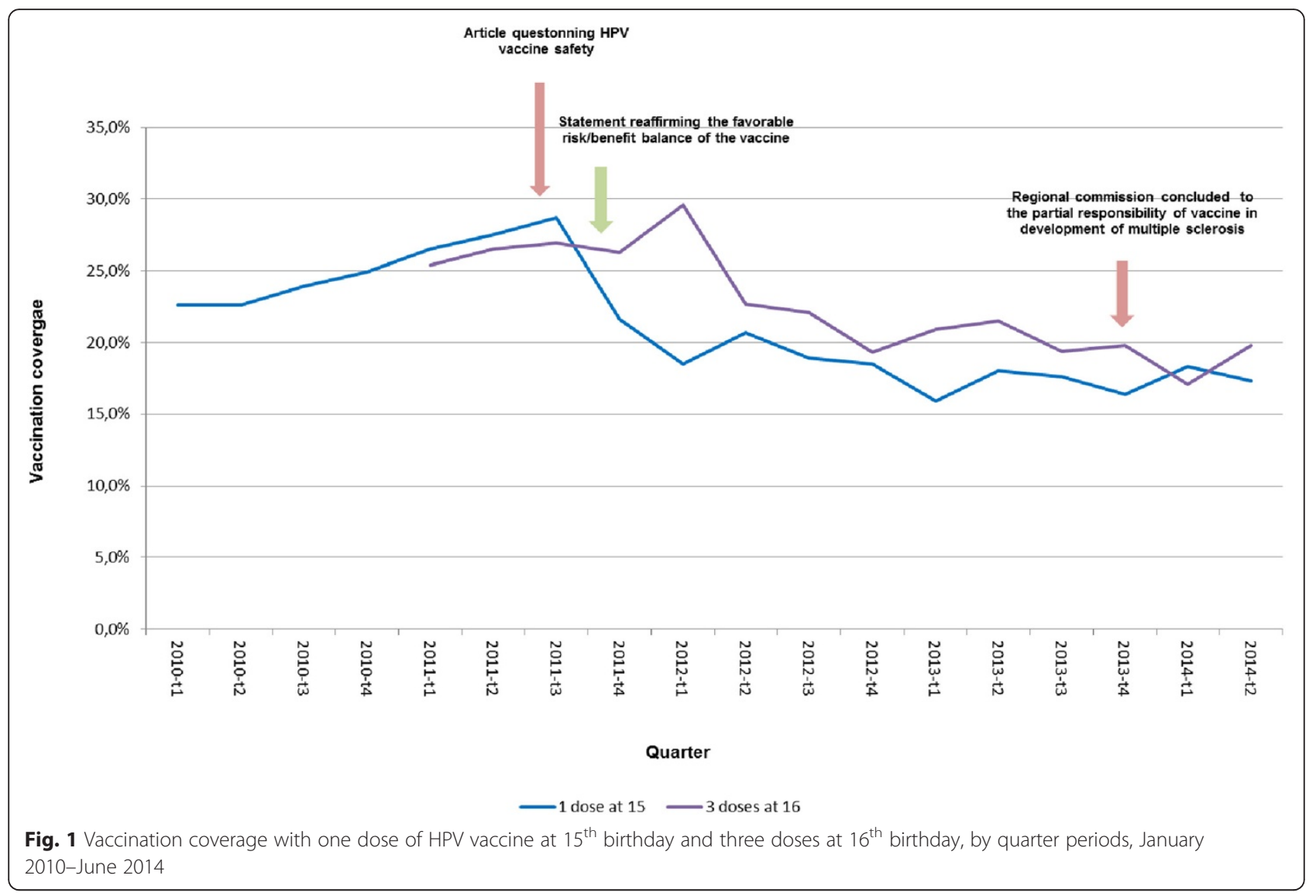

positive statement from the High Council for Public Health was not reported in the media and therefore could not impact favorably the HPV vaccination coverage. The social concerns related to the vaccine safety profile and the relevance of HPV vaccination in addition to screening are likely to have negatively affected HPV vaccination coverage and contributed to the very low level observed in 2014.

We were able to closely monitor the vaccination coverage trends through the use of vaccine reimbursement data. This new method represents an innovative approach to provide timely updated reliable vaccination

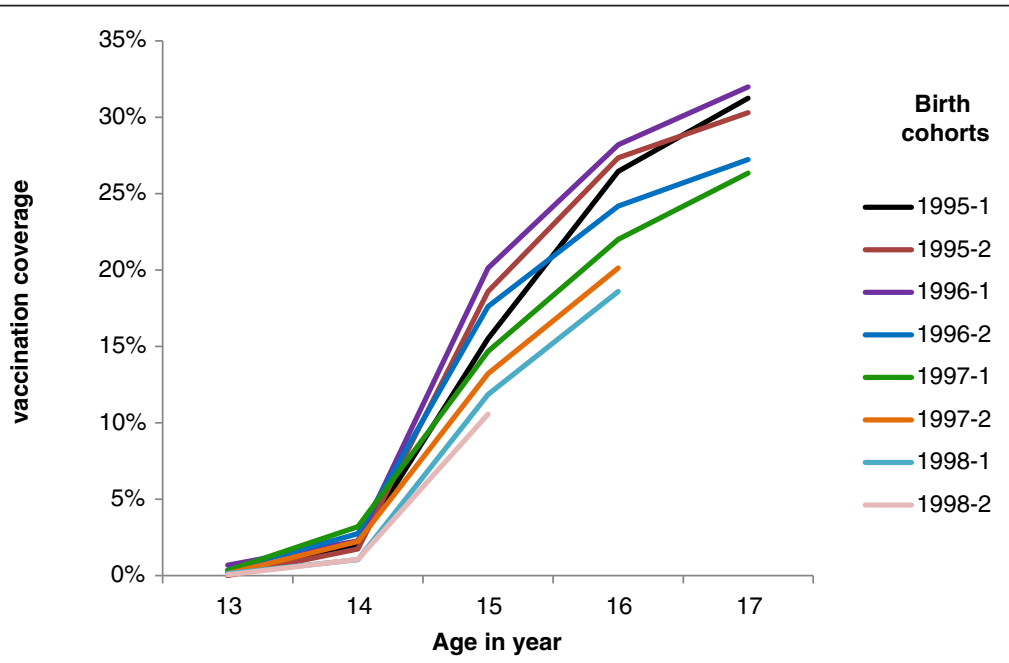

Fig. 2 Cumulative vaccination coverage for 3 doses of HPV vaccine according to age and half year of birth. France 
coverage estimates. The time between actual delivery of the vaccine by the pharmacist and availability of the information in the PSB is only around 1 month. Beneficiaries are selected totally randomly. Indeed the beneficiaries with a strictly secret value of their National Identity Register (NIR) control key number (going from 1 to 97) are selected and included in the PSB whether they have consumed care or not. The validity of the PSB as a vaccine coverage measurement tool was previously validated through the comparison of the mumps measles and rubella (MMR) vaccination coverage estimated through the PSB and through the Child Health Certificate $(\mathrm{CHC})$ which is our reference tool. MMR vaccine coverage estimates for one dose at 24 months for the 2010 birth cohort was very close: $91.4 \%$ from PSB and $90.5 \%$ through the CHC [10]. Our PSB estimates agree well with the few available other data. Our $23.7 \%$ coverage for one dose among girls aged 15 years old in 2010 is consistent with the results of a school survey in which $24.7 \%$ of girls aged on average 15 years old in 2009 had received one dose of HPV vaccine [5]. Our estimated coverage for complete vaccination of $24.2 \%$ among girls aged 16 in 2012 is also consistent with the results of a survey in which $23.6 \%$ of girls aged 15 years old in 2012 were fully immunized against HPV [11]. To our knowledge, except some experiences in Germany [12, 13], reimbursement data has not been used for the estimation of vaccination coverage in other European Countries [14]. It represents a cheaper and easier alternative to ad hoc surveys which can be very resource consuming. This source of data is particularly useful to monitor coverage in age groups such as teenagers usually not targeted by vaccination strategies and for which routine vaccination monitoring tools are lacking in many countries.

The use of PSB has some limitations. First, our analysis focused on the beneficiaries of the General Health Insurance Scheme covering only $77 \%$ of the population and no data comparing the vaccination attitudes of the population according to their insurance coverage were available until recently. However, since 2011, data from two other schemes, covering an extra $10 \%$ of the population, have been progressively integrated in the PSB. Vaccination coverage for one dose among 15 years old girls born in 1998 covered by these schemes, was $18.9 \%$ (95 \% CI [12.9-24.9]) and $18.5 \%$ (95 \% CI [12.6-24.3]), respectively, consistent with our estimation (95\% CI (17.8 \% [16.4-19.2]). We were unable to estimate vaccination coverage after the age of 17 years because at this age, many girls become students and are no longer registered in the General Health Insurance Scheme. Limited information on factors that could have influenced the vaccine coverage is available in the PSB. However, the proportion of individuals registered in the PSB and benefiting from the Universal Health Care Coverage, which gives full free access to care to the most disadvantaged ones, did virtually not change during the study period. This indicator can be considered as a proxy of the socio-economic status of the PSB beneficiaries. Furthermore, the vaccination offer did not change during the study period.

Last, purchased vaccines may not all be administered and some persons may purchase their vaccine without claiming for reimbursement. There is no data to estimate the frequency of such situations, but we believe this to be very rare, especially for expensive vaccines such as HPV ones.

Some measures have been taken to try to improve the HPV vaccination coverage. A new report summarizing internationally available evidence regarding the safety, effectiveness and impact of HPV vaccination was prepared by the Public Health Council (HCSP) and published on its website on September 2014 to address the controversy [15]. To the same end, the French Institute for Health Promotion and Education has developed a community management plan for HPV vaccination to be implemented in 2016 in order to give official answers to concerns raised and questions asked on internet forums. Changes in the immunization schedule aiming at increasing the compliance to HPV vaccination recommendations has been made in 2014: the target age for routine vaccination has been enlarged from 14 to 11-14 years and the number of doses needed in this age group has been reduced from three to two [16].

\section{Conclusions}

In conclusion HPV vaccination coverage was very low in France in 2011 and decrease afterwards probably in relation with media coverage regarding potential safety issues of the vaccine. The Permanent Sample of Beneficiaries was particularly useful to rapidly assess the impact of public concerns on HPV vaccination coverage. A new vaccine coverage assessment will be made by end-2015 and will allow measuring the impact on the recently implemented countermeasures on HPV vaccine coverage.

\section{Abbreviations \\ HCSP: Public Health Council; HPV: Human papillomavirus; InVS: National Institute for Public Health Surveillance; NHIS: National Health Insurance Scheme; PSB: Permanent Sample of Beneficiaries (PSB); HCSP: Public Health Council.}

\section{Competing interests}

All authors declare that they have no competing interests.

\section{Authors' contributions}

LF made the analysis and wrote the first draft of the manuscript. MR updated the data, IP, JPG and DLB contributed to the interpretation of the data and the discussion. DLB helped revising the manuscript. All authors read and approved the final version. 


\section{Acknowledgements}

We would like to acknowledge the CNAM-TS for providing us with the PSB data and Pawel Stefanoff and Isabelle Parent du Châtelet for reviewing the manuscript.

\section{Author details}

'Institut de Veille Sanitaire (InVS), Saint-Maurice, France. ${ }^{2}$ European Programme for Intervention Epidemiology Training (EPIET), European Centre for Disease Prevention and Control, (ECDC), Stockholm, Sweden.

Received: 16 March 2015 Accepted: 4 December 2015

Published online: 12 December 2015

\section{References}

1. Woronoff AS, Trétarre B, Guizard AV, Arveux P. Colde I'utérus. In: BinderFoucard F, Belot A, Delafosse P, Remontet L, Woronoff AS, Bossard N, editors. National estimate of the incidence and mortality from cancer in France between 1980 and 2012 - A study based on Francim network of cancer registries - Part 1 - Solid Tumors. Saint-Maurice: Institut de veille sanitaire; 2013. p. 122. Available online: http://www.invs.sante.fr/Publicationset-outils/Rapports-et-syntheses/Maladies-chroniques-et-traumatismes/2013/ Estimation-nationale-de--incidence-et-de-la-mortalite-par-cancer-en-Franceentre-1980-et-2012. Accessed on February 10, 2015.

2. Centre national de référence des Papillomavirus humains (CNR HPV), Institut Pasteur. Available online: http://www.pasteur.fr/fr/sante/info-hp. Accessed on February 2, 2015.

3. Haut Conseil de la santé publique (HCSP). 2012 vaccination schedule and recommendations from the «Haut Conseil de la santé publique » in France. Bull Epidémiol Hebd. 2012;14-15. Available online: http://www.invs.sante.fr/ Publications-et-outils/BEH-Bulletin-epidemiologique-hebdomadaire/ Archives/2012/BEH-n-14-15-2012. Accessed on February 17, 2015.

4. Haut Conseil de la santé publique (HCSP). Infections à HPV des jeunes filles: révision de l'âge de vaccination; 2012. Available online: http://www.hcsp.fr/ Explore.cgi/avisrapportsdomaine?clefr=302. Accessed on February 2, 2015.

5. Haut Conseil de la santé publique (HCSP). Avis relatif au vaccin Gardasi ${ }^{\circledR}$ et à la stratégie de prévention globale des cancers du col de l'utérus. $21^{\text {st }}$ October 2011. Available online: http://www.hcsp.fr/explore.cgi/ avisrapportsdomaine? clefr=454. Accessed on February 10, 2015.

6. Chardon O, Guignon N. La santé des adolescents scolarisés en classe de troisième. Etudes et résultats. DREES; 2014;865. Available online: http://www.drees.sante.gouv.fr/la-sante-des-adolescents-scolarises-enclasse-de-troisieme,11247.html. Accessed on February 21, 2015.

7. Antona D, Fonteneau L, Lévy Bruhl D, Guignon N, De Peretti C, Niel X, et al. Vaccination coverage of children and adolescents in France: results of schoolbased surveys, 2001-2004. Bull Epidémiol Hebd. 2007;7. Available online: http://www.invs.sante.fr/beh/2007/06/. Accessed on February 24, 2015.

8. Tuppin P, de Roquefeuil L, Weill A, Ricordeau P, Merliere Y. French national health insurance information system and the permanent beneficiaries sample. Rev Epidemiol Sante Publique. 2010;58:286-90.

9. De Roquefeuil L, Studer A, Neumann A, Meliere Y. The Echantillon généraliste de bénéficiaires: representativeness, scope and limits. Prat Organ Soins. 2009;40(3):213-23.

10. Fonteneau L, Ragot M Guthmann J-P, Lévy-Bruhl D. Use of health care reimbursement data to estimate vaccination coverage in France: example of, hepatitis $B$, meningitis $C$ and human papillomavirus vaccination. Rev Epidemiol Sante Publique, 2015, 00362-4.

11. Cohen R, Denis F, Gaudelus J, Lery T, Lepetit H, Martinot A, et al. Immunization coverage: Teenagers are in danger... Status on the occasion of vaccination week. Med Mal Infect. 2012;42:139-40.

12. Reuss AM, Feig M, Kappelmayer L, Siedler A, Eckmanns T, Poggensee G. Varicella vaccination coverage of children under two years of age in Germany. BMC Public Health. 2010;10:502. Available online: http://www. biomedcentral.com/1471-2458/10/502. Accessed on February 17, 2015.

13. Kalies $H$, Redel $R$, Varga $R$, Tauscher M, von Kries R. Vaccination coverage in children can be estimated from health insurance data. BMC Public Health 2008:8:82. Available online: http://www.biomedcentral.com/1471-2458/8/82. Acessed on February 2, 2015.

14. Venice II Consortium. Vaccination coverage assessment in EU/EEA, 2011. 2012. Available online: http://venice.cineca.org/Final_Vaccination_Coverage_ Assesment_Survey_2011_1.pdf. Accessed on February 17, 2015.
15. Haut Conseil de la santé publique (HCSP). Vaccination contre les infections à papillomavirus humain. HCSP; 2014. Available online: http://www.hcsp.fr/ explore.cgi/avisrapportsdomaine? clefr=454. Accessed on February 10, 2015.

16. Calendrier des vaccinations et recommandations vaccinales 2014. INPES; 2014. Available online: http://www.sante.gouv.fr/IMG/pdf/Calendrier_ vaccinal_ministere_2.pdf

\section{Submit your next manuscript to BioMed Central and we will help you at every step:}

- We accept pre-submission inquiries

- Our selector tool helps you to find the most relevant journal

- We provide round the clock customer support

- Convenient online submission

- Thorough peer review

- Inclusion in PubMed and all major indexing services

- Maximum visibility for your research

Submit your manuscript at www.biomedcentral.com/submit
Biomed Central 